\title{
Research on cost-based AGC pricing mechanism for China's wind power
}

\author{
Zeng Yiping ${ }^{{ }^{1}}$, Zhao Xingang ${ }^{1}$, Wang Ling $^{2}$ \\ ${ }^{1}$ School of Economics and Management, North China Electric Power Univ., Beijing 102206, China \\ ${ }^{2}$ State Grid Liaoning Electric power co., LTD. Benxi Power Supply Company, Benxi, 117000, China \\ *zengyp309@sina.com
}

Keyword: Wind power; AGC pricing mechanism; China

\begin{abstract}
With the large-scale development of China's wind power industry recently, wind power con-nected to grid has great impacts on power system network FM (frequency modulation). Researching on pric-ing mechanism of AGC ancillary service is essential for the stability and economy of ancillary services markets of power system. This paper summarizes the current China's wind power development status and proposes the necessity of AGC pricing mechanism. In consideration of the costs of AGC, we propose the cost-based AGC pricing mechanism for China's wind power. And the establishment of AGC pricing model is used to analyze four typical wind farms in four regions of Chinese nationwide. The reasonable AGC pricing mechanism is discussed and the costbased AGC compensation mechanism is designed as a reference for the future AGC ancillary service pricing.
\end{abstract}

\section{INSTRUCTION}

Currently, China's power market is constantly improved. AGC (Automatic Generation Control) is one of the paid ancillary services provide by the grid-connected power plants. As an important FM services, AGC provide important technical support for power system stable operation and optimize the allocation of resources.

Providing AGC ancillary service will generate corresponding costs. In order to improve the initiative of power plants to support AGC, the power plants provide AGC ancillary services need to be compensated.

In recent years, a large number of scholars have made a lot of researches on China's wind power industry development and ancillary services compensation. AGC pricing and compensation mechanism are mainly including cost pricing and market pricing [Li Yanqing et al. 2012]. AGC cost pricing generally takes investment costs, operation and maintenance costs and the opportunity costs into consideration [Wang Juanjuan et al. 2010][ Tao Chunhua. 2006]. Because of the incomplete information, it is difficult to measure whole costs that AGC unit provides ancillary services. However, the methods of costs pricing provides a theoretical basis for market pricing. Using probabilistic methods and random simulation on AGC, the opportunity costs of AGC unit provides ancillary services can be estimated [Yan Maosong and Zou Bin. 2003]. According to grid load characteristics and AGC adjustment condition, the AGC benchmark obligations adjustment levels should be developed for the power plants and the AGC grid deal model can be established [Xia Wei. 2012]. Li Dan et al. construct comprehensive indicators to evaluation the AGC performance and propose appropriate methods of AGC compensation [Li Dan et al. 2010].

This paper focuses on the design of cost-based AGC pricing mechanism with the consideration of the current status of the development of China's wind power and the costs of the AGC. The establishment of AGC pricing model is used to analyze four typical wind farms in four regions of Chinese nationwide. The reasonable AGC pricing mechanism is discussed and the cost-based AGC compensation mechanism is designed as a reference for the future AGC ancillary service pricing.

\section{CHINA'S WIND POWER STATUS QUO}




\subsection{Installed capacity}

Figure 1 shows the installed capacity of China's wind power from 2006 to 2009. It can be seen that from 2006 to 2010, the growth rates of China's wind power installed capacity are very high. The installed capacity of China's wind power maintained a steady growth trend year by year after 2010. As of 2014, the cumulative installed capacity of China's wind power reached to $114.61 \mathrm{GW}$. According to the "National Energy 'Thirteen Five planning", the installed capacity of wind power will exceed 200 million and the price of wind power will reach to coal tariff considerably in 2020.

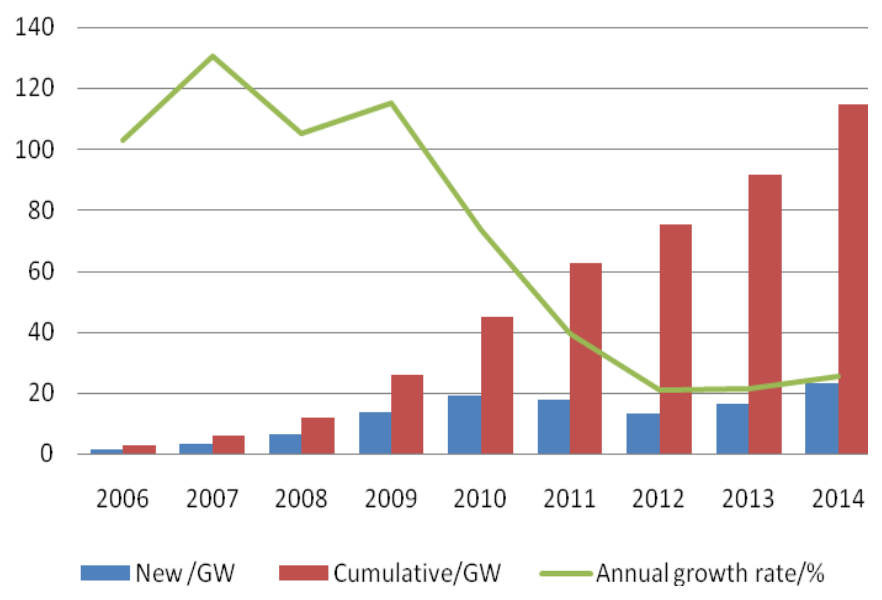

Figure 1. Installed capacity of China’s wind power from 2006 to 2009

Source: [Yuanxin Liu et al. 2015]

At present, China's wind power has already entered a comprehensive, rapid and large-scale development phase. In 2014, the national development and construction of wind power were significantly improved. The approval of new wind power capacity is about 36 million $\mathrm{kW}$. The total approved capacity is 173 million $\mathrm{kW}$.

\subsection{Wind curtailment and AGC}

The development of China's wind power industry has a good momentum. However, the gridconnected and integration issues of wind power led to a serious problem of wind curtailment. The issue of wind curtailment has become a major restriction for the healthy and sustainable development of China's wind power. Wind curtailment statistic of Chinese nationwide from 2012 to 2014 is shown in Figure 2.

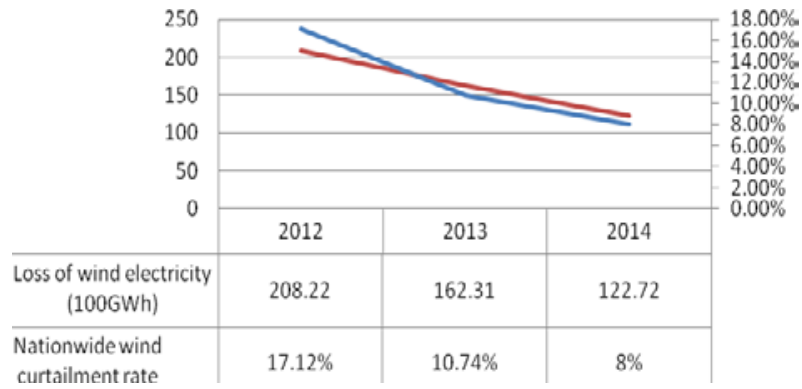

Figure 2. Wind curtailment statistic of Chinese nationwide from 2012 to 2014

It is shown in Figure 2 that the highest wind curtailment rate is in 2012, reaching 17.12\%. From 2012 to 2014, wind curtailment rate is declining. By the end of 2014, the wind curtailment rate reached $8 \%$. The decreasing of wind curtailment rate is mainly due to the wind conditions is generally small in 2014. The increase of wind power generating capacity is reduced. It reduces the market absorption pressure objectively. Meanwhile, the National Energy Administration has taken macrocontrol measures to strictly limit new construction scale in wind curtailment areas which has also achieved some success in 2012-2014.

In the long term, wind curtailment problems seriously affect the confidence of the development of wind power thereby affect subsequent manufacturers' initiative to invest in wind power genera- 
tion. To solve the problem of wind curtailment, we need to improve the regional wind power consumptive capacity and enhance the enthusiasm of conventional power participation in peak regulation. Wind power provides AGC ancillary service as a new way to solve the problems of wind curtailment and other issues.

As one of environment-friendly renewable energy, the biggest shortcomings of wind power is that wind power output has a greater randomness. It cannot guarantee to provide reliable, stable power. In order to maintain a stable grid frequency, the requirements for AGC adjustment capacity will significantly increase after wind power integration. Therefore, it is particularly necessary to develop a reasonable wind power AGC pricing mechanism to improve the cost sharing and compensation.

\section{AGC PRICING MECHANISM FOR CHINA'S WIND POWER}

Certain contract services unit of AGC electricity, which the power plant and the dispatch center had earlier signed for, is arranged by dispatch centers to ensure AGC unit operation within an adjustable range. AGC provides certain services, and trying to complete the contract power at the same time. There are two cases:

(1)When AGC services provided by the AGC units can't complete electricity contract, partially electricity of compensation capacity could come up with matching the opportunity cost of the compensation charge. At that time, the power of unfinished contract will roll backwards. Thus, the AGC units increase the contract power, which is also a form of compensation AGC services;

(2) When the AGC unit provides services and completes daily contract electricity, it may have extra power. The extra power, according to AGC unit marginal price, can be denoted as equation (1):

Costing AGC unit obtained $=$ AGC ancillary service price $\times$ excess power

The AGC ancillary service of contract, in addition to the regular price settlement, also need AGC service compensation.

This paper mainly discusses the case (2). Existing rules mainly provide compensation standards for conventional support services. We can estimate the cost of the wind power plant to provide AGC ancillary services. This price can fluctuate within a range.

\subsection{Cost-based AGC pricing}

\subsubsection{AGC investment costs and operation and maintenance costs}

In order to provide AGC services, the wind power plant must modify a part of equipment. This investment should be included in the AGC service costs and ensure the return on investment within the service life. The transformation of the wind power plant governor and the computer monitoring system is included. If the grid operators and service providers signed a year service contracts, the annual cost-sharing device model acquires AGC services through bilateral negotiation. Then, the grid operators shall pay $C_{y}$ annually to service providers.

$$
C_{y}=C_{i n v} \frac{i(1+i)^{n}}{(1+i)^{n}-1}
$$

$C_{i n v}$ is the AGC equipment investment cost; $\mathrm{n}$ is the service life of the equipment; $\mathrm{i}$ is the weighted average rate of return on capital.

The approximate cost of AGC adjustable capacity is:

$$
C_{f c}=\frac{C_{y}}{365 \times 24 Q_{c}}
$$

$Q_{c}$ is the adjustable capacity of wind farms 
Once wind farms install the AGC system, it will take equipment operation and maintenance costs for AGC system. According to Figure 3, the operation and maintenance costs are about one-third of investment in equipment. Operation and maintenance costs can be denoted as follows:

$$
C_{r u n}=C_{f c} / 3
$$

The total investment costs and operation and maintenance costs can be denoted as follows:

$$
C_{f r}=C_{f c}+C_{r u n}
$$

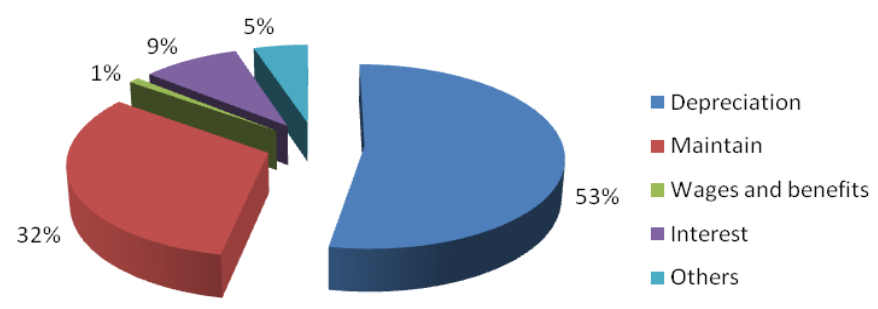

Figure 1. The cost structure of wind farms

\subsubsection{Extra abrasion costs}

Equipment service life studies show: unit reduces the operational life of about 10-15 hours per on-off time. And due to AGC service maintenance units have 150 on-off times will have $20 \%$ reduction in operating life. Considering this part of reduction in operating life, the wind power plants can calculate the cost of this part of costs of depreciation rates.

$$
\begin{aligned}
& C_{e x}=C_{s} /(25-20 \% \times 25)-C_{s} / 25=C_{s} / 100 \\
& =C_{d} / 4 \\
& =R_{d} C_{\rho} / 4
\end{aligned}
$$

$C_{s}$ is the total investment of the wind farm unit; $C_{d}$ is equal share of the total investment in 25 years, approximately equal to the depreciation costs of unit equipment operation; $R_{d}$ is the wind power depreciation accounted for 53 percent in the cost of power generation; $C_{e}$ is the power generation costs of wind power (unit: \$/MWh).

\subsubsection{Opportunity cost}

AGC adjust capacity always set aside a certain margin. This part of loss is opportunity cost. In order to improve wind farm enthusiasm to participate in ancillary services and improve grid security and power quality, opportunity costs should be compensated.

$$
C_{c h}=P_{e}
$$

$P_{e}$ is the wind power tariff

With the rapid development of China's wind power industry, the tender price policy is no longer suitable. In July 2009, the NDRC (National Development and Reform Commission) released "a notice on the sound of wind power tariff policy ". According to this notice, NDRC has established the regional benchmark feed-in tariff. Onshore wind power tariff must refer to the regional benchmark feed-in tariff. As Table 1 shows, the nationwide is divided into four categories of wind energy resource areas. Four resource zones have different benchmark feed-in tariffs for China's onshore wind power. 
Table 1. Benchmark feed-in tariffs for China's onshore wind power

\begin{tabular}{ccccc}
\hline $\begin{array}{c}\text { Resource } \\
\text { Zone }\end{array}$ & I & II & III & IV \\
\hline $\begin{array}{c}\text { Benchmark } \\
\text { feed-in tar- } \\
\text { iff }\end{array}$ & $\begin{array}{c}86.92 \$ / \\
\text { MWh }^{\circledR}\end{array}$ & $\begin{array}{c}92.04 \$ / \\
\text { MWh }\end{array}$ & $\begin{array}{c}98.85 \$ / \\
\text { MWh }\end{array}$ & $\begin{array}{c}100.97 \$ / \\
\text { MWh }\end{array}$ \\
\hline
\end{tabular}

Sources: [Yuanxin Liu et al. 2015]

\subsection{Empirical analysis}

Based on the above analysis and calculation, it can be drawn that: the total cost of the wind farm AGC should include equipment investments, operation and maintenance costs, opportunity costs and abrasion costs.

The entire AGC device system includes software, auxiliary and spare parts. The contract price of AGC system is about 45070 dollars according to the AGC quote data. Assume the weighted average return on equity is $10 \%$ and the service life is 25 years. Assume the unit capacity is $99 \mathrm{MW}$ and the adjustable capacity of wind farm is about 30MW. Four regional wind power electricity prices are shown in Table 1 . The average profit margin of China's five major power generation groups is about $6 \%$. It can be assumed that the average profit margins of four wind farms in four regions are $6 \%$.

The calculation costs of wind farm AGC ancillary service in four resource areas are shown in the table 2 .

Table 2. Costs of wind farm AGC ancillary service in four resource areas

\begin{tabular}{llll}
\hline Resource Zone & $\begin{array}{l}\text { AGC investment costs and } \\
\text { operation and maintenance } \\
\text { costs }\end{array}$ & Abrasion costs & Opportunity cost \\
\hline I & $0.0257 \$ /$ MWh & $10.82 \$ /$ MWh & $86.92 \$ /$ MWh \\
\hline II & $0.0257 \$ /$ MWh & $10.82 \$ /$ MWh & $92.04 \$ /$ MWh \\
\hline III & $0.0257 \$ /$ MWh & $10.82 \$ /$ MWh & $98.85 \$ /$ MWh \\
\hline IV & $0.0257 \$ /$ MWh & $10.82 \$ / M W h$ & 100.97 /MWh \\
\hline
\end{tabular}

(1) Because the electricity contract settlement has been liquidated basic electricity price. When auxiliary services provide the electricity belongs to the contractual part, additional compensation can be denoted as:

$$
C_{0}=C_{f r}+C_{g x}
$$

(2)When auxiliary services provide the electricity exceeds the contractual part, AGC pricing model can be denoted as follows:

$$
C_{0}=C_{f r}+C_{g x}+C_{c h}
$$

The AGC compensation prices in four resource areas are shown in table 3.

Table 3. AGC compensation prices in four resource areas

\begin{tabular}{lcccl}
\hline Resource Zone & I & II & III & IV \\
\hline $\mathrm{C}_{0}$ (unit: \$/ MWh) & 97.76 & 102.88 & 109.93 & 114.81 \\
\hline
\end{tabular}

Currently AGC compensation price in grid were all similar as formula (9). The total compensation is equal to the basic price plus additional compensation in essence.

\section{CONCLUSION}

The large-scale wind power connected to grid systems brings great impacts to FM. Correct and reasonable assessment of the cost price of power system AGC ancillary services is crucial to the se-

(1) Exchange Rates on June 26, 2015: 1\$=6.2123RMB. The further occurrences will be the same. 
curity and economy of the power system and auxiliary services market. Based on the current situation and characteristics of wind power AGC ancillary service, the establishment of wind power AGC ancillary service cost-based pricing mechanism can promote effective cost apportionments. The cost-based AGC pricing strategy for wind power can be referenced in the future practice.

\section{ACKNOWLEDGMENT}

This article is supported by "Science and technology project funding by State Grid Liaoning electric power co., LTD. Benxi Power Supply Company” (Grant No. FZJS1400820 and FZJS1400829) and Science and technology project funding by State Grid Corporation.

\section{REFERENCES}

[1] Li Yanqing, Ge Man, Wang Yang. 2012. Research on fuzzy analytic hierarchy process based AGC compensation. Electric Power Science and Engineering 28(11): 22-27

[2] Wang Juanjuan, Li Weidong, Zhao Lei. 2010. Cost studies AGC ancillary service in electricity market- A review. Power system protection and control 38 (24): 56-61

[3] Tao Chunhua, Ma Guangwen. 2006. Research on AGC cost in electricity market environment. East China Electric Power (34) 4: 5-6

[4] Yan Maosong, Zou Bin. 2003. New pricing method of AGC prior assessment and post-test probability studies. Electric Power Systems 27 (2): 1-6

[5] Xia Wei. 2012. Large-scale wind power included research on grid AGC transactions. Hydropower Engineering 30 (04): 195-198

[6] Li Dan, Liang Ji, Sun Rongfu. 2010. Plant management and network regulation performance appraisal system AGC compensation measures. Electric Power Systems 34 (4): 107-111

[7] Yuanxin Liu et al. 2015. The industrial performance of wind power industry in China. Renewable and Sustainable Ener-gy Reviews 43: 644-655. 